Separations of $f$ Elements, proceedings of a symposium at the $207^{\text {th }}$ Annual Meeting of the American Chemical Society (Eds. Kenneth L. Nash, Gregory R. Choppin)

\title{
SEPARATION OF AMERICIUM FROM EUROPIUM BY SOLVENT EXTRACTION FROM AQUEOUS PHOSPHONATE MEDIA
}

Dale D. Ensor Chemistry Department Tennessee Technological University Cookeville, TN 38505

and

Kenneth L. Nash

Chemistry Division Argonne National Laboratory Argonne, IL 60439

The stoichiometry and stability constants for americium and europium complexes with phosphonoacetic acid $\left(\mathrm{HO}_{2} \mathrm{CCH}_{2} \mathrm{PO}_{3} \mathrm{H}_{2}-\mathrm{PAA}\right)$ in dilute acid solutions $(0.005$ to $0.02 \mathrm{M})$ have been determined by distribution methods at $0.5 \mathrm{M}$ ionic strength and $25.0^{\circ} \mathrm{C}$. The identified Am and $\mathrm{Eu}$ complexes and $\log \beta_{m h l}$ values are $\mathrm{Am}\left(\mathrm{H}_{2} \mathrm{~L}\right)^{2+}-13.82( \pm 0.04), \mathrm{Am}(\mathrm{HL})^{+}$. 11.62( \pm 0.04$), \quad \mathrm{Am}\left(\mathrm{H}_{2} \mathrm{~L}\right)_{2}{ }^{+}-27.35( \pm 0.01), \mathrm{Eu}(\mathrm{HL})^{+}-12.10( \pm 0.05), \mathrm{Eu}\left(\mathrm{H}_{2} \mathrm{~L}\right)_{2}{ }^{+}$$27.81( \pm 0.01), \mathrm{Eu}(\mathrm{HL}) 2^{-}-23,08( \pm 0.05)$. The Eu complexes are stronger than Am complexes of comparable stoichiometry, in accord with the electrostatic nature of the metal -ligand interaction. PAA was tested as a potential agent of enhanced $\mathrm{Am} / \mathrm{Eu}$ separation in solvent extraction systems by examining Am and Eu extraction using different extractants. For extraction into bis(2-ethythexyl)phosphoric acid (HDEHP), PAA slightly reduces the Am/Eu separation factor. With dinonylnapthalenesulfonic acid (HDNNS), or octyl(phenyl)-N,N-diisobutyl- carbamoylmethylphosphine oxide (CMPO)-nitrate extraction systems, $S_{\mathrm{Eu}}{ }^{A m}$ is slightly enhanced by PAA. A three fold increase in $S_{\mathrm{Eu}}{ }^{A m}$ is observed in CMPO extraction from $0.5 \mathrm{M} \mathrm{KSCN/PAA}$ media (over extraction from $0.5 \mathrm{M} \mathrm{KSCN}$ ) suggesting an improved method for lanthanide/trivalent actinide separation.

Work performed under the auspices of the Office of Basic Energy Sciences, Division of Chemical Sciences, U. S. Department of Energy, under contract W-31-109-ENG-38 


\section{DISCLAIMER}

Portions of this document may be illegible in electronic image products. Images are produced from the best available original document. 


\section{INTRODUCTION}

The intra- and intergroup separation of trivalent actinide and lanthanide elements remains one of the most challenging and important problems in separation science. These elements play a significant role in the development of methods for cleanup and decommissioning of nuclear facilities and the long-term storage of high-level waste. Advanced concepts for actinide burnup either in reactors or by accelerator transmutation demand efficient methods for separation of lanthanides from actinides. A recent review article on trivalent $f-$ element separations (1) noted that most of the successful group separations were based on systems combining lipophilic ex tractants with aqueous complexing reagents.

Both polycarboxylic and aminocarboxylic acids have been used in felement separations. Recent work at Argonne has focussed on the thermodynamics of lanthanide and actinide complexes with phosphonic acid complexants. One of the objectives of this work has been to assess the potential of these reagents for use in lanthanide/actinide separations. Stability constants for $E u(I I I)(2), T h(I V)$ (3), and U(VI) (4) complexes with a wide variety of substituted diphosphonic acids have been measured. These reagents show a significant increase in complexing strength over their carboxylate analogs. The relative stability of the metal complexes is consistent with an electrostatic bonding model for these elements. It has been demonstrated that substituted methanediphosphonic acids are particularly efficient for stripping radioactivity from loaded organic phases in solvent extraction (5).

Little data is available on the complexation of the trivalent actinide ions with these phosphonate ligands. Elesin et al (6) report stability constants for the $\mathrm{M}\left(\mathrm{H}_{2} \mathrm{~L}\right)^{2+}, \mathrm{MHL}^{+}$, and $\mathrm{M}(\mathrm{HL})_{2}{ }^{-}$complexes of $\mathrm{Pm}(\mathrm{III}), \mathrm{Am}(\mathrm{III})$, and Cm(III) with phosphonoacetic acid(PAA). Their reported constants exhibit little difference in complex stability between the three metals. However, aspects of their methodology cast doubt on the absolute value of the constants.

In this work we report the stoichiometry and stability constants for Eu(III) and Am(III) complexes with PAA. Subsequently, the ability of PAA to enhance group separation of lanthanides and actinides was investigated by determining the distribution of $A m(I I I)$ and Eu(III) from aqueous solutions of PAA into extractant solutions containing an acidic extractant (bis(2-ethylhexyl) phosphoric acid - HDEHP), a micellar extractant (dinonylnaphthalene sulfonic acid - HDNNS), and a neutral bifunctional extractant (octyl(phenyl)-N,Ndiisobutylcarbamoylmethylphosphine oxide - CMPO) from nitrate and thiocyanate media.

\section{EXPERIMENTAL}

\section{Reagents}

PAA, 99\%, was obtained from the Aldrich Chemical Company and used without further 
purification. The extractants HDEHP, HDNNS, and CMPO were purified before use by wellknown methods taken from the literature. Reagent grade toluene was used to prepare most of the extractant solutions. Diethyl benzene was the diluent for the CMPO solutions. All other reagents used were analytical reagent grade or better.

\section{Procedures}

Potentiometry. Stock solutions of PAA were prepared and standardized by potentiometric titration using $\mathrm{NaOH}$. Ionic strength was controlled at $0.5 \mathrm{M}$ using $\mathrm{NaNO}_{3}$ as the supporting electrolyte. A Ross combination electrode was used as the $\mathrm{pH}$ probe. The electrode was calibrated by titrating $0.01 \mathrm{M} \mathrm{HNO}_{3}, 0.49 \mathrm{M} \mathrm{NaNO}_{3}$ with $0.10 \mathrm{M} \mathrm{NaOH}, 0.40 \mathrm{M}$ $\mathrm{NaNO}_{3}$. The data provided a $\mathrm{pH}-\mathrm{p}[\mathrm{H}]$ calibration curve for conversion of the measured hydrogen ion activity to hydrogen ion concentration. Titrimetric analyses were performed using a Mettler DL21 titrator with associated $T S^{2}$ software for data acquisition. Gran plots were made to determine titration endpoints. Protonation constants for PAA were calculated as reported previously (2).

Distribution Measurements. The ${ }^{241}$ Am and ${ }^{152-154}$ Eu stock solutions were prepared from lab stocks by repeated evaporations to dryness in concentrated $\mathrm{HNO}_{3}$ followed by final dissolution in 0.01M HNO $3,0.49 \mathrm{M} \mathrm{NaNO}_{3}$. Radiotracers were assayed using Packard Cobra Auto Gamma counter. The experiments for determination of Am-PAA stability constants were run in dual-label experiments with both ${ }^{241} \mathrm{Am}$ and ${ }^{152-4} \mathrm{Eu}$ present simultaneously using HDEHP as the extractant. The Am(III) counting channel covered the 60 kev $\gamma$-ray emission. The Eu channel included the Eu $\gamma$-rays between 100-700 kev. Each isotope's count rate was corrected for spill-over from the other based on prepared standards. Because the $D_{0}(E u)$ values were too high in the dual label experiments for accurate stability constant determination, EuPAA stability constants were determined in single label experiments. Separation factors with HDNNS and CMPO extraction systems were measured in dual-labeled experiments.

All distribution experiments were done at $25^{\circ} \mathrm{C}$ and $0.50 \mathrm{M}$ ionic strength (adjusted with $\mathrm{HNO}_{3} / \mathrm{NaNO}_{3}$ ). For the determination of stability constants, PAA concentrations were varied between 0 and $0.40 \mathrm{M}$. This procedure was repeated at $\left[\mathrm{H}^{+}\right]=0.005,0.01$, and $0.02 \mathrm{M}$. Under each set of experimental conditions at least two replicate experiments were performed with freshly prepared solutions. To maximize precision in the resolved stability constants, the concentration of HDEHP was varied with acidity to maintain the measured $D_{0}$ ([PAA] $=0$ ) between 5 and 20. All PAA solutions were prepared by volumetric dilution of a stock solution which had been standardized by potentiometric titration. Eu/Am separation factors with different extractants were measured at PAA concentrations between 0 and $0.34 \mathrm{M}$. The aqueous phase ionic strength was $0.5 \mathrm{M}\left(\mathrm{HNO}_{3} / \mathrm{NaNO}_{3}\right)$ in the HDNNS experiments while $\left[\mathrm{NaNO}_{3}\right]$ or $[\mathrm{KSCN}]$ was maintained at $0.5 \mathrm{M}$ in the CMPO experiments. 


\section{RESULTS AND DISCUSSION}

\section{Ligand Protonation and Metal Complex Stability}

The protonation constants of PAA were calculated using the program PKAS (7). The results of the potentiometric titrations of free PAA shown in Table 1 are the average of five determinations at various PAA concentrations. Earlier reports at $2 \mathrm{M}$ ionic strength (3) and infinite dilution (8) are consistent with the present results. The first and third protonation reactions describe association of hydrogen ions with the phosphonate group, the second hydrogen ion associates with the carboxylate. This sequence has been previously confirmed by Heubel and Popov (8) based on ${ }^{31} \mathrm{P}$ and ${ }^{13} \mathrm{C}$ NMR spectroscopy. Comparison of the acidity of the $-\mathrm{CO}_{2}{ }^{-}$and $-\mathrm{PO}_{3}=$ groups in PAA with the $\mathrm{pK}$ 's of analogous monoacids suggests that each group has minimal effect on the relative basicity of the other or perhaps that the sharing of

Table 1. Protonation Constants for PAA and related ligands at $25^{\circ} \mathrm{C}$.

\begin{tabular}{|l|c|c|c|c|c|}
\hline Ligand & $\mathrm{pK}_{1}$ & $\mathrm{pK}_{2}$ & $\mathrm{pK}_{3}$ & Conditions & Reference \\
\hline PAA & $\begin{array}{c}1.12 \\
(0.15)\end{array}$ & $\begin{array}{c}4.66 \\
(0.02)\end{array}$ & $\begin{array}{c}7.69 \\
(0.02)\end{array}$ & $\begin{array}{c}\mathrm{I}=0.5 \mathrm{M}, \\
\mathrm{NaNO}_{3}\end{array}$ & present work \\
\hline $\mathrm{PAA}$ & $\begin{array}{c}0.92 \\
(0.10)\end{array}$ & $\begin{array}{c}4.57 \\
(0.01)\end{array}$ & $\begin{array}{c}7.23 \\
(0.01)\end{array}$ & $\begin{array}{c}\mathrm{I}=2.0 \mathrm{M} \\
\mathrm{NaClO}\end{array}$ & 3 \\
\hline $\mathrm{PAA}$ & 2.0 & 5.11 & 8.69 & $\mathrm{I}=0$ & 8 \\
\hline $\mathrm{CH}_{3} \mathrm{CH}_{2} \mathrm{PO}_{3}^{2-}$ & 2.29 & 7.79 & & $\mathrm{I}=0.1 \mathrm{M}$ & 9 \\
\hline $\mathrm{CH}_{3} \mathrm{CH}_{2} \mathrm{CO}_{2}^{-}$ & 4.69 & & & $\mathrm{I}=0.1 \mathrm{M}$ & 9 \\
\hline
\end{tabular}

hydrogen ions by the two functional groups offsets the inductive effect.

To calculate the stability constants for the Am and Eu PAA complexes, it is first necessary to correct the distribution data for the presence of nitrate complexes. The stability constant for $\mathrm{EuNO}_{3}{ }^{2+}$ at $0.5 \mathrm{M}$ ionic strength $\left(\log \beta_{\mathrm{EuNO}_{3}}=0.44\right)$ was taken from Martell (9). Appropriate stability constants for $\mathrm{AmNO}_{3}{ }^{2+}\left(\log \beta_{\mathrm{AmNO}_{3}}=0.38\right.$ ) were extrapolated from existing data at higher ionic strength by comparing the Am $B$ 's with more extensive data on EuNO ${ }_{3}^{2+}$. The distribution data as a function of $[\mathrm{PAA}]$ and $\left[\mathrm{H}^{+}\right]$were reduced to the form $\mathrm{D} / \mathrm{D}-1-\mathrm{B}_{\mathrm{MNO}_{3}}\left[\mathrm{NO}_{3}\right]$. Averaged distribution data used to determine stoichiometry and stability of the Am-PAA and Eu-PAA complexes are shown in Figures 1 and 2 respectively. In Table 2 we have included the complete data set for Am.

Preliminary analysis of the data consisted of plots of $\mathrm{D}_{\mathrm{o}} / \mathrm{D}-1-\mathrm{B}_{\mathrm{MNO}_{3}}\left[\mathrm{NO}_{3}{ }^{-}\right]\left(\mathrm{D}_{0} / \mathrm{D}-1-\mathrm{C}\right.$ for simplicity) vs. $\left[\mathrm{PAA}^{3-}\right]$ at constant acidity. These plots were fit by a quadratic expression, 
Table 2. Distribution data for $\mathrm{Am}^{3+}+\mathrm{PAA}$ at $25^{\circ} \mathrm{C}, \mathrm{I}=0.5 \mathrm{M}\left(\mathrm{NaNO}_{3}\right)$.

\begin{tabular}{|c|c|c|c|c|c|}
\hline$[\mathrm{PAA}]_{\mathrm{t}}$ & {$\left[\mathrm{H}^{+}\right]$} & $D_{0}$ & $\mathrm{D}$ & $D_{\alpha} / D-1-C$ & $\sigma\left(D_{0} / D-1-C\right)$ \\
\hline 0.01 & 0.005 & 6.942 & 2.320 & 0.7923 & 0.0658 \\
\hline 0.01 & 0.005 & 6.942 & 2.426 & 0.6615 & 0.0540 \\
\hline 0.02 & 0.005 & 6.942 & 1.973 & 1.319 & 0.109 \\
\hline 0.02 & 0.005 & 6.942 & 2.118 & 1.078 & 0.089 \\
\hline 0.04 & 0.005 & 6.942 & 1.354 & 2.926 & 0.235 \\
\hline 0.04 & 0.005 & 6.942 & 1.332 & 3.013 & 0.268 \\
\hline 0.07 & 0.005 & 6.942 & 0.793 & 6.558 & 0.538 \\
\hline 0.07 & 0.005 & 6.942 & 0.815 & 6.317 & 0.518 \\
\hline 0.1 & 0.005 & 6.942 & 0.574 & 9.900 & 0.780 \\
\hline 0.1 & 0.005 & 6.942 & 0.586 & 9.643 & 0.867 \\
\hline 0.15 & 0.005 & 6.942 & 0.330 & 18.86 & 1.49 \\
\hline 0.15 & 0.005 & 6.942 & 0.350 & 17.63 & 1.42 \\
\hline 0.2 & 0.005 & 6.942 & 0.233 & 27.58 & 2.26 \\
\hline 0.2 & 0.005 & 6.942 & 0.223 & 28.88 & 2.34 \\
\hline 0.01 & 0.01 & 10.17 & 3.518 & 0.6902 & 0.0550 \\
\hline 0.01 & 0.01 & 10.17 & 3.935 & 0.3840 & 0.0339 \\
\hline 0.02 & 0.01 & 10.17 & 2.354 & 2.120 & 0.808 \\
\hline 0.02 & 0.01 & 10.17 & 3.502 & 0.7038 & 0.0600 \\
\hline 0.04 & 0.01 & 10.17 & 2.168 & 2.489 & 0.213 \\
\hline 0.04 & 0.01 & 10.17 & 2.329 & 2.167 & 0.175 \\
\hline 0.07 & 0.01 & 10.17 & 1.399 & 5.070 & 0.440 \\
\hline 0.07 & 0.01 & 10.17 & 1.438 & 4.872 & 0.404 \\
\hline 0.1 & 0.01 & 10.17 & 1.085 & 7.170 & 0.759 \\
\hline 0.1 & 0.01 & 10.17 & 1.051 & 7.471 & 0.619 \\
\hline 0.15 & 0.01 & 10.17 & 0.597 & 14.83 & 1.29 \\
\hline 0.15 & 0.01 & 10.17 & 0.599 & 14.76 & 1.25 \\
\hline 0.2 & 0.01 & 10.17 & 0.412 & 22.47 & 1.78 \\
\hline 0.2 & 0.01 & 10.17 & 0.433 & 21.29 & 1.76 \\
\hline 0.0194 & 0.02 & 19.78 & 6.592 & 0.8001 & 0.0474 \\
\hline 0.0194 & 0.02 & 19.78 & 6.302 & 0.9384 & 0.0530 \\
\hline 0.0485 & 0.02 & 19.78 & 4.598 & 2.102 & 0.135 \\
\hline 0.0485 & 0.02 & 19.78 & 4.618 & 2.082 & 0.137 \\
\hline 0.0727 & 0.02 & 19.78 & 3.220 & 3.942 & 0.223 \\
\hline 0.0727 & 0.02 & 19.78 & 3.088 & 4.204 & 0.254 \\
\hline 0.0921 & 0.02 & 19.78 & 2.560 & 5.527 & 0.283 \\
\hline 0.0921 & 0.02 & 19.78 & 2.553 & 5.547 & 0.360 \\
\hline 0.145 & 0.02 & 19.78 & 1.672 & 9.632 & 0.654 \\
\hline 0.145 & 0.02 & 19.78 & 1.662 & 9.700 & 0.617 \\
\hline 0.242 & 0.02 & 19.78 & 0.830 & 21.64 & 1.252 \\
\hline 0.242 & 0.02 & 19.78 & 0.841 & 21.31 & 1.192 \\
\hline 0.339 & 0.02 & 19.78 & 0.422 & 44.61 & 2.309 \\
\hline 0.339 & 0.02 & 19.78 & 0.427 & 44.13 & 2.716 \\
\hline
\end{tabular}




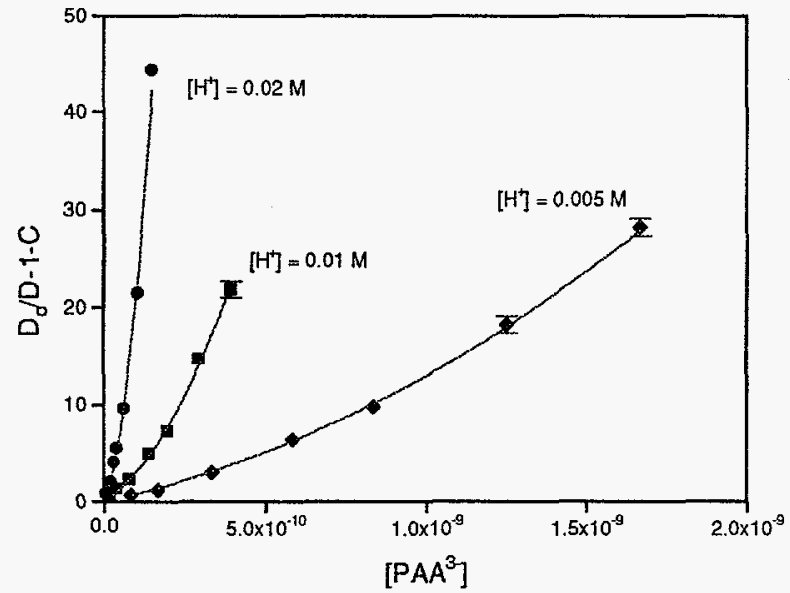

Figure 1 Distribution data and least-squares fit for Am-PAA system. Extraction into various

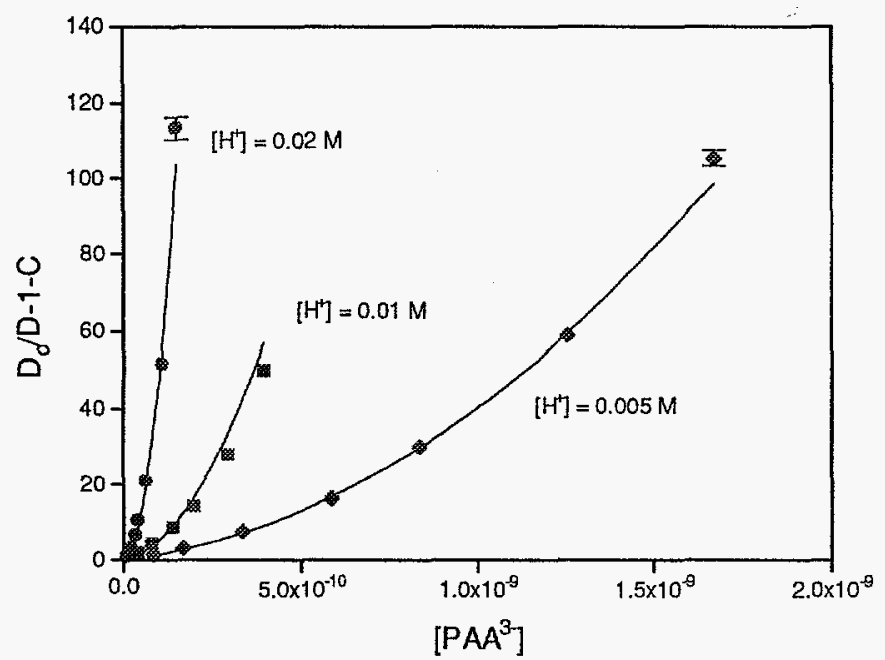

Figure 2 Distribution data and least-squares fit for Eu-PAA system. Extraction into various concentrations of HDEHP in toluene. The term $\mathrm{C}$ on the y axic label represents $\mathrm{B}_{\mathrm{MNO}_{3}}\left(\mathrm{NO}_{3}{ }^{-}\right]$. 
indicating $M: L$ stoichiometries of $1: 1$ and 1:2. The resolved conditional constants varied with the acidity to indicate the stoichiometry of the $1: 1$ and $1: 2$ complexes with respect to $\left[\mathrm{H}^{+}\right]$. The hydrogen ion dependence for the $1: 1$ and $1: 2$ complexes of Am were $1.66( \pm 0.01)$ and $3.92( \pm 0.01)$ respectively, suggesting the presence of the species $\mathrm{MH}_{2} \mathrm{~L}^{2+}, \mathrm{MHL}^{+}$, and $\mathrm{M}\left(\mathrm{H}_{2} \mathrm{~L}\right)_{2}{ }^{+}$. The corresponding values for Eu were $0.92( \pm 0.54)$ and 3.59( \pm 0.03$)$ indicating the dominant species were $\mathrm{MHL}^{+}, \mathrm{M}\left(\mathrm{H}_{2} \mathrm{~L}\right)_{2}{ }^{+}$, and $\mathrm{M}(\mathrm{HL})_{2}{ }^{-}$. Data files like those represented in Table 2 were fit using a nonlinear least-squares program described previously (2). The following fit equation was used to adjust the data:

$$
D_{d} / D-1-C=\beta_{121}\left[H^{+}\right]^{2}\left[L^{3-}\right]+\beta_{111}\left[H^{+}\right]\left[L^{3-}\right]+\beta_{142}\left[H^{+}\right]^{4}\left[L^{3-}\right]^{2}+\beta_{122}\left[H^{+}\right]^{2}\left[L^{3-}\right]^{2}
$$

The $\sigma$ 's in Table 2 are based primarily on radioactivity counting statistics for the determination of distribution ratios $D$ and $D_{0}$. All other sources of error were considered to contribute equally to the uncertainty of the individual points. The data were fit using $1 / \sigma$ as the weighting factor.

Neither set of data supported all four of the model parameters in equation $1\left(\beta_{121}, \beta_{111}\right.$, $\beta_{142}, \beta_{122}$ ), but each system was best described by a different three parameter equation. The best fit parameters are given in Table 3. The solid lines in Figures 1 and 2 are the least squares fit lines calculated using the stability constants in Table 3. Stepwise constants for $\mathrm{Am}\left(\mathrm{H}_{2} \mathrm{~L}\right) / \mathrm{Am}\left(\mathrm{H}_{2} \mathrm{~L}\right)_{2}\left(\log \mathrm{K}_{121}=13.82( \pm 0.04), \log \mathrm{K}_{142}=13.53( \pm 0.04)\right)$ show only a factor of 2 decrease for addition of the second $\mathrm{H}_{2} \mathrm{~L}$ ligand to the $1: 1$ complex implying that the strength of interaction of the second ligand with $\mathrm{Am}^{3+}$ is effected little by the presence of the first. For europium, the step-wise constants for $\mathrm{Eu}(\mathrm{HL})^{+} / \mathrm{Eu}(\mathrm{HL})_{2}{ }^{-}$are $12.10( \pm 0.05)$ and $10.98( \pm 0.07)$ respectively. Here, the 1:2 complex is an order of magnitude weaker than the 1:1 complex, perhaps reflecting the greater perturbation of the inner coordination sphere of Eu by the doubly ionized $\mathrm{H}(\mathrm{PAA})^{2-}$ anion. The relatively greater importance of $\mathrm{H}(\mathrm{PAA})^{2-}$ in the Eu system

Table 3.Stability constants for americium and europium complexes with phosphonoacetic acid at $25^{\circ} \mathrm{C}^{\mathrm{a}}$.

\begin{tabular}{|c|c|c|c|c|c|}
\hline Metal & $\log \beta_{121}$ & $\log \beta_{111}$ & $\log \beta_{142}$ & $\log \beta_{122}$ & I, ref \\
\hline $\mathrm{Am}^{3+}$ & $13.82(0.04)$ & $11.62(0.04)$ & $27.35(0.01)$ & - & $0.5 \mathrm{M}, \mathrm{p} . w$. \\
\hline $\mathrm{Eu}^{3+}$ & - & $12.10(0.05)$ & $27.81(0.01)$ & $23.08(0.05)$ & $0.5 \mathrm{M}, \mathrm{p} . w$. \\
\hline $\mathrm{UO}_{2}^{2+}$ & 15.42 & 13.91 & 29.87 & 26.50 & $0.1 \mathrm{M}, 4$ \\
\hline $\mathrm{Th}^{4+}$ & 15.73 & - & 30.51 & - & $2.0 \mathrm{M}, 3$ \\
\hline
\end{tabular}

reflects stronger electrostatic attraction of the smaller $\mathrm{Eu}^{3+}$ cation for the ligand.

Besides the present results, earlier data on $\mathrm{UO}_{2}{ }^{2+}(4)$ and $\mathrm{Th}^{4+}(3)$ are included in Table 3. Only the $\mathrm{M}\left(\mathrm{H}_{2} \mathrm{~L}\right)_{2}$ complex is common to all four systems. The relative order of complex 
stability for this series is $\mathrm{Am}^{3+}<\mathrm{Eu}^{3+}<\mathrm{UO}_{2}{ }^{2+}<\mathrm{Th}^{4+}$. This order is consistent with expectation, though the uranyl complexes appear to be exceptionally strong, perhaps reflecting a favorable contribution to overall complex stability by hydrogen bonding interactions between the protonated phosphonate group and the uranyl oxygens. The stepwise constants for both uranyl and thorium show an order-of-magnitude dropoff for addition of the second ligand, similar to the Eu-PAA system.

\section{Am/Eu Separation Factors}

The net separation factor for metal ions in a solvent extraction process which uses

$$
S_{B}^{A}=\frac{D^{A}}{D^{B}}=\frac{D_{0}^{A}\left(1+\Sigma \beta_{1}^{B}[L]\right)}{D_{0}^{B}\left(1+\Sigma \beta_{i}^{A}[L]\right)}
$$

aqueous complexes is described by equation 2 :

where $D_{0}$ represents the distribution of the respective metal ions in the absence of aqueous complexes and $\beta$ 's are the stability constants of the respective metal ions. It is clear from this equation that the separation factors of $\mathrm{A}$ from $\mathrm{B}$ are directly dependent on their relative extraction but inversely dependent on the relative stability of their aqueous complexes. For the most efficient separation, both the extractant and the aqueous complexant must have appropriate properties.

In the case of HDEHP, literature reports and the $D_{0}$ values determined herein indicate that $\mathrm{Eu}$ is extracted about 30 times more efficiently than $\mathrm{Am}\left(\log \mathrm{K}_{\mathrm{ex}}{ }^{\mathrm{Eu}}=-1.06, \log \mathrm{K}_{\mathrm{ex}}{ }^{\mathrm{Am}}=\right.$ 2.61, after correction for nitrate complexes). Since the Eu-PAA complexes are more stable than those of Am, the extractant and complexant ligands in this system work in the opposite sense resulting in lower separation factors when the complexant is present than when it is absent. At $0.01 \mathrm{M}$ acid and $[\mathrm{HDEHP}]=0.15 \mathrm{M}$, the distribution ratios and separation factors are $\mathrm{D}_{\mathrm{Am}}=$ $4.49, \mathrm{D}_{\mathrm{Eu}}=140$, and $\mathrm{S}_{\mathrm{Eu}}{ }^{\mathrm{Am}}=0.032$. For extraction from 0.2 M PAA solutions under the same conditions, the corresponding values are $\mathrm{D}_{\mathrm{Am}}=0.42, \mathrm{D}_{\mathrm{Eu}}=8.22$, and $\mathrm{S}_{\mathrm{Eu}}{ }^{\mathrm{Am}}=0.051$. Calculations based on the resolved stability constants as applied in equation 2 reproduce the latter results. Similar results were obtained at $0.005 \mathrm{M}$ acid.

Sulfonic acid extractants like HDNNS are known to exhibit little selectivity when extracting metal ions of the same charge (1). Because the $D_{0}{ }^{A} / D_{0}{ }^{B}$ term in equation 2 is near 1 , the aqueous complexant should enhance Am/Eu separation efficiency in this system. In duallabel experiments using $0.0112 \mathrm{M}$ HDNNS in toluene as the extractant, the following results were obtained at $0.02 \mathrm{M}$ acid, $0.5 \mathrm{M} \mathrm{NaNO}_{3}: \mathrm{D}_{\mathrm{Am}}=16.1, \mathrm{D}_{\mathrm{Eu}}=19.4$, and $\mathrm{SEu}_{\mathrm{Em}}{ }^{\mathrm{Am}}=0.83$. For extraction from $0.34 \mathrm{MPAA}$ at $\left[\mathrm{H}^{+}\right]=0.02 \mathrm{M}$ and $0.5 \mathrm{M} \mathrm{NaNO}_{3}$, the observed distribution ratios and separation factors are: $\mathrm{D}_{\mathrm{Am}}=1.70, \mathrm{D}_{\mathrm{Eu}}=0.94$, and $\mathrm{S}_{\mathrm{Eu}}{ }^{\mathrm{Am}}=1.81$. Corresponding values calculated from the experimental $D_{0}$ values and the resolved stability constants are: $D_{A m}$ $=0.79, \mathrm{D}_{\mathrm{Eu}}=0.42$, and $\mathrm{S}_{\mathrm{Eu}}{ }^{\mathrm{Am}}=1.88$. While the separation factor is consistent, the distribution ratios are lower than the experimental values suggesting the possible partial extraction of both 
the Eu and Am-PAA complexes by HDNNS.

Neutral bifunctional extractants like CMPO also exhibit little lanthanide/actinide selectivity when extracting these metal ions from nitrate media (1). When thiocyanate is the counter ion, actinide/lanthanide separation factors average about $7(10,11)$. This result is related to the stronger interaction between actinides and the soft donor $\mathrm{SCN}^{-}$. Since actinides are more strongly extracted from this system and the europium complexes with PAA are more stable, both the $\mathrm{D}_{0}{ }^{\mathrm{Am}} / \mathrm{D}_{0}{ }^{\mathrm{Eu}}$ and $\left(1+\Sigma \beta_{m h l}\left[\mathrm{H}^{+}\right]^{h}\left[\mathrm{~L}^{3-}\right]^{h}\right)$ Eu $/\left(1+\Sigma \beta_{m h l}\left[\mathrm{H}^{+}\right]^{h}\left[\mathrm{~L}^{3-}\right]^{\prime}\right)$ Am terms of equation 2 are favorable. The separation factors in both the nitrate and thiocyanate systems could be improved by the addition of an aqueous complexant like PAA. Because the systems offer additional parameters for adjustment of the relative D's, we have examined only a few selected sets of conditions. These conditions do not necessarily represent the optimized configuration for these systems.

The distribution ratios and separation factors for $\mathrm{Am}$ and Eu extraction by $0.5 \mathrm{M}$ CMPO-diethylbenzene from $0.5 \mathrm{M} \mathrm{NaNO}_{3}$ at $\mathrm{pH} 1.88$ are $\mathrm{D}_{\mathrm{Am}}=110, \mathrm{D}_{\mathrm{Eu}}=107$, and $\mathrm{S}_{\mathrm{Eu}}{ }^{\mathrm{Am}}=$ 1.03. When 0.2 M PAA is introduced into the aqueous phase, the corresponding values are $D_{A m}$ $=4.57, \mathrm{D}_{\mathrm{Eu}}=2.21$, and $\mathrm{S}_{\mathrm{Eu}}{ }^{\mathrm{Am}}=2.07$. Distribution ratios calculated from the experimental $\mathrm{D}_{\mathrm{o}}$ values (corrected for the mononitrate complex in the aqueous phase) and the stability constants reported in Table 3 are $\mathrm{D}_{\mathrm{Am}}=10.7$ and $\mathrm{D}_{\mathrm{Eu}}=5.00\left(\mathrm{SEu}_{\mathrm{Em}}=2.14\right)$. The experimental separation factor is well described by the calculation, but the distribution ratios are lower than the calculated values. At $0.3 \mathrm{M}$ PAA, the discrepancy between experimental and calculated distribution ratios is larger while the separation factors are still consistent. We cannot at present explain this observation, but it may be related to the procedures used to preequilibrate the extractant phase or perhaps to the extraction of mixed ligand complexes.

The CMPO - thiocyanate system was investigated at $\mathrm{pH} 1.88-2.00,0.05 \mathrm{M}$ CMPOdiethylbenzene, $0.5 \mathrm{M} \mathrm{KSCN}$, and [PAA] between 0 and $0.3 \mathrm{M}$. The $\mathrm{D}_{0}$ values were corrected for $\mathrm{AmSCN}^{2+}(B=4.0)$ and $\mathrm{EuSCN}^{2+}(B=2.4)$ complexes in the aqueous phase using the stability constants of Kinard and Choppin (12). Their constants were determined at $5.0 \mathrm{M}$ ionic strength and so may not be appropriate for $0.5 \mathrm{M}$ media. The average distribution ratios for replicate experiments done with slightly different extractant preconditioning procedures are $\mathrm{D}_{\mathrm{Am}}=25.8, \mathrm{DEu}_{\mathrm{Eu}}=4.30$, and $\mathrm{S}_{\mathrm{Eu}} \mathrm{Am}=6.00$, consistent with literature reports for similar conditions. At both $0.1 \mathrm{M}$ and $0.2 \mathrm{M} \mathrm{PAA}$, the Am/Eu separation potential is enhanced: $0.1 \mathrm{M}$ $\mathrm{PAA}, \mathrm{D}_{\mathrm{Am}}=4.82, \mathrm{D}_{\mathrm{Eu}}=0.42$, and $\mathrm{S}_{\mathrm{Eu}}{ }^{\mathrm{Am}}=11.6 ; 0.2 \mathrm{MPAA}, \mathrm{D}_{\mathrm{Am}}=1.24, \mathrm{D}_{\mathrm{Eu}}=0.084$, and $\mathrm{S}_{\mathrm{Eu}}{ }^{\mathrm{Am}}=14.7$. Calculations based on the experimental $\mathrm{D}_{\circ}{ }^{\prime}$ and $B^{\prime} \mathrm{s}$ in $\mathrm{T}$ able 3 again reproduce the separation factors, but predict higher distribution ratios. Further experiments are planned to optimize and further test and optimize this system for actinide/lanthanide separations.

\section{CONCLUSION}

Complexes between $\mathrm{Am}^{3+}$ or $\mathrm{Eu}^{3+}$ and phosphonoacetic acid differ in relative stability 
in accord with the electrostatic model of cation binding. The smaller Eu ${ }^{3+}$ cation forms stronger complexes with PAA than the larger $\mathrm{Am}^{3+}$ cation. The observed metal complexes in the acid range from $0.005 \mathrm{M}$ to $0.02 \mathrm{M}$ (at $\mathrm{I}=0.5 \mathrm{M}$ ) are $\mathrm{Eu}(\mathrm{HL})^{+}, \mathrm{Eu}\left(\mathrm{H}_{2} \mathrm{~L}\right)_{2}{ }^{+}, \mathrm{Eu}(\mathrm{HL})_{2}{ }^{-}$and $\mathrm{Am}\left(\mathrm{H}_{2} \mathrm{~L}\right)^{2+}, \mathrm{Am}(\mathrm{HL})^{+}, \mathrm{Am}\left(\mathrm{H}_{2} \mathrm{~L}\right)_{2}{ }^{+}$. When used as a holdback reagent, PAA slightly enhances the separation of Am/Eu when used with sulfonic acids or CMPO/nitrate, but reduces separation efficiency with HDEHP. In a $\mathrm{CMPO} \mathrm{SCN}^{-}$extraction system which favors extraction of Amover Eu, addition of PAA increases the separation efficiency by a factor of 2-3 at $0.3 \mathrm{M}$ PAA/0.5 M SCN . The calculated stability constants can be used to explain the separation factors, but do not always accurately predict metal distribution ratios in the CMPO systems, implying that there are details of this system which have not been fully elucidated.

\section{REFERENCES}

1. K. L. Nash Solv. Extr. Ion Exch. 11729 (1993).

2. K. L. Nash Inorg. Chim. Acta 169245 (1990).

3. K. L. Nash Radiochim. Acta 54171 (1991).

4. K. L. Nash Radiochim. Acta 61147 (1993).

5. E. P. Horwitz, H. Diamond, R. C. Gatrone, K. L. Nash, P. G. Rickert "TUCS: A new class of aqueous complexing agents for use in solvent extraction processes" in Solvent Extraction 1990 (ed. T. Sekine) Elsevier Science Publishers (1992) pp. 357-362.

6. A. A. Elesin, A. A. Zaitzeva, S.S. Kazakova, G. N. Yakovlev Radiokhimiya 14541 (1972).

7. A. E. Martell and R. J. Motekaitis Determination and Use of Stability Constants VCH Publishers New York (1988).

8. P. C. Heubel and A. I. Popov J. Soln. Chem. 8615 (1979).

9. NIST Database 46. Critical Stability Constants of Metal Complexes Database, Version 1.0, R. M. Smith, A. E. Martell, R. J. Motekaitis, U. S. Department of Commerce, Gaithersburg, Md. September, 1993.

10. A. C. Muscatello, E. P. Horwitz, D. G. Kalina, L. Kaplan Sepn. Sci. Technol. 17859 (1982).

11. E. P. Horwitz, A. C. Muscatello, Unpublished work, 1981.

12. W. F. Kinard and G. R. Choppin J. Inorg. Nucl. Chem. 361131 (1974). 